OPEN ACCESS

Edited and reviewed by: Christian Nawroth Leibniz Institute for Farm Animal

Biology (FBN), Germany

*Correspondence:

Miho Nagasawa

nagasawa@carazabu.com

Specialty section:

This article was submitted to

Comparative Psychology

a section of the journal

Frontiers in Psychology

Received: 23 December 2020 Accepted: 04 February 2021 Published: 01 March 2021

Citation:

Koyasu H, Kikusui T, Takagi S and Nagasawa M (2021) Corrigendum: The Gaze Communications Between

Dogs/Cats and Humans: Recent

Research Review and Future Directions. Front. Psychol. 12:645366.

doi: 10.3389/fpsyg.2021.645366

\section{Corrigendum: The Gaze} Communications Between Dogs/Cats and Humans: Recent Research Review and Future Directions

\author{
Hikari Koyasu ${ }^{1,2}$, Takefumi Kikusui ${ }^{1}$, Saho Takagi ${ }^{1,2}$ and Miho Nagasawa ${ }^{1 *}$ \\ ${ }^{1}$ Laboratory of Human-Animal Interaction and Reciprocity, Azabu University, Kanagawa, Japan, ${ }^{2}$ Japan Society for the \\ Promotion of Science, Tokyo, Japan
}

Keywords: dogs, cats, humans, gaze, interaction, communication, bond

\section{A Corrigendum on}

The Gaze Communications Between Dogs/Cats and Humans: Recent Research Review and Future Directions

by Koyasu, H., Kikusui, T., Takagi, S., and Nagasawa, M. (2020). Front. Psychol. 11:613512. doi: $10.3389 /$ fpsyg.2020.613512

In the original article, there was a mistake in Table 1 as published. The references for the entry "Looked alternately at the food and the owner when it could access the food" (section "social reference") were incorrect. The corrected Table 1 appears below.

The authors apologize for this error and state that this does not change the scientific conclusions of the article in any way. The original article has been updated. 
TABLE 1 | Gaze communication between dogs/cats and humans.

\begin{tabular}{|c|c|c|c|}
\hline Dogs & References & Cats & References \\
\hline \multicolumn{4}{|l|}{ Response to human gaze } \\
\hline Stole food less often & Call et al., 2003; Kaminski et al., 2013 & Avoided the gaze of familiar human & Koyasu and Nagasawa, 2019 \\
\hline $\begin{array}{l}\text { Obeyed more commands of their } \\
\text { owners }\end{array}$ & Schwab and Huber, 2006 & $\begin{array}{l}\text { Selected food from humans who looked at } \\
\text { them }\end{array}$ & Ito et al., 2016 \\
\hline
\end{tabular}

Fetched the toy that humans Call et al., 2003

could see in the situation with

two toys

Increased attention-getting

Ohkita et al., 2016

behaviors

Selected food from humans who Gácsi et al., 2004

looked at them

\section{Using human signals}

Used human pointing in the task Miklosi et al., 2005

of selecting one of two

containers

Used human gaze direction with

pointing in the task of selecting

one of two containers

Looked in the direction directed

by human gaze (with head

movements)

Followed the container that humans visited in a situation with two food containers

\section{Social reference}

Looked alternately at the food and the owner when it could access the food

Looked alternately at the strange

object and the owner

\section{The role of gaze in bond formation}

Increased attention-getting Ohkita et al., 2016

behaviors in dogs, which

function as attachment behaviors

in response to human gaze

Dog owner's oxytocin secretion increased in response to the dog's gaze

An oxytocin-mediated positive loop of bond formation facilitated and modulated by gazing, like mother-infant

Eyeblink synchronization during mutual gazing
Hare et al., 2002

Hare et al., 1998; Agnetta et al., 2000; Téglás et al., 2012; Met et al., 2014

Chijiiwa et al., 2020; Nagasawa et al., 2020

Miklosi et al., 2005, Lazzaroni et al., 2020

Merola et al., 2012a,b

Nagasawa et al., 2009

Nagasawa et al., 2015

Koyasu et al., 2020
Used human pointing in the task of selecting one of two containers

Looked in the direction indicated by

human gaze (with head movements)

Followed the container that humans visited in a situation with two food containers
Miklosi et al., 2005

Pongrácz et al., 2019

Chijiiwa et al., 2020
Did not look alternately at the food and the owner when it could not access the food

Looked alternately at the strange object and the owner

Eyeblink synchronization during mutual gazing
Miklosi et al., 2005

Merola et al., 2015

Koyasu et al., 2020

\section{REFERENCES}

Agnetta, B., Hare, B., and Tomasello, M. (2000). Cues to food location that domestic dogs (Canis familiaris) of different ages do and do not use. Anim. Cogn. 3, 107-112. doi: 10.1007/s100710000070

Call, J., Bräuer, J., Kaminski, J., and Tomasello, M. (2003). Domestic dogs (Canis familiaris) are sensitive to the attentional state of humans. J. Comp. Psychol. 117:257. doi: 10.1037/0735-7036.117.3.257

Chijiiwa, H., Takagi, S., Arahori, M., Hori, Y., Saito, A., and Kuroshima, H. (2020). Dogs and cats prioritize human action: choosing a now-empty instead of a stillbaited container. Anim. Cogn. doi: 10.1007/s10071-020-01416-w [Epub ahead of print].

Gácsi, M., Miklósi, A., Varga, O., Topál, J., and Csányi, V. (2004). Are readers of our face readers of our minds? Dogs (Canis familiaris) show situation-dependent recognition of human's attention. Anim. Cogn. 7:144. doi: 10.1007/s10071-003-0205-8

Hare, B., Brown, M., Williamson, C., and Tomasello, M. (2002). The domestication of social cognition in dogs. Science 298, 1634-1636. doi: 10.1126/science.1072702

Hare, B., Call, J., and Tomasello, M. (1998). Communication of food location between human and dog (Canis familiaris). Evol. Commun. 2, 137-159. doi: 10.1075/eoc.2.1.06har

Ito, Y., Watanabe, A., Takagi, S., Arahori, M., and Saito, A. (2016). Cats beg for food from the human who looks at and calls to them: 
ability to understand humans'attentional states. Psychologia 59, 112-120. doi: $10.2117 /$ psysoc.2016.112

Kaminski, J., Pitsch, A., and Tomasello, M. (2013). Dogs steal in the dark. Anim. Cogn. 16:385. doi: 10.1007/s10071-012-0579-6

Koyasu, H., Goto, R., Takagi, S., Nakano, T., Nagasawa, M., and Kikusui, T. (2020). "Mutual synchronization of eyeblinks between dogs/cats and humans," in Proceedings of the 80th Annual Meeting of the Japanese Society for Animal Psychology, Suita.

Koyasu, H., and Nagasawa, M. (2019). Recognition of directed-gaze from humans in cats. Jpn. J. Anim. Psychol. 69, 2-3.

Lazzaroni, M., Marshall-Pescini, S., Manzenreiter, H., Gosch, S., Pøibilová, L., and Darc, L. (2020). Why do dogs look back at the human in an impossible task? Looking back behaviour may be over-interpreted. Anim. Cogn. 23:427. doi: 10.1007/s10071-020-01345-8

Merola, I., Lazzaroni, M., Marshall-Pescini, S., and Prato-Previde, E. (2015). Social referencing and cat-human communication. Anim. Cogn. 18, 639-648. doi: 10.1007/s10071-014-0832-2

Merola, I., Prato-Previde, E., and Marshall-Pescini, S. (2012a). Dogs' social referencing towards owners and strangers. PLoS One 7:e47653. doi: 10.1371/journal.pone.0047653

Merola, I., Prato-Previde, E., and Marshall-Pescini, S. (2012b). Social referencing in dog-owner dyads? Anim. Cogn. 15, 175-185. doi: 10.1007/s10071-011-0443-0

Met, A., Miklósi, Á, and Lakatos, G. (2014). Gaze-following behind barriers in domestic dogs. Anim. Cogn. 17:1401. doi: 10.1007/s10071-014-0754-z

Miklosi, A., Pongracz, P., Lakatos, G., Topal, J., and Csanyi, V. (2005). A comparative study of the use of visual communicative signals in interactions between dogs (Canis familiaris) and humans and cats (Felis catus) and humans. J. Comp. Psychol. 119, 179-186. doi: 10.1037/0735-7036.119.2.179
Nagasawa, M., Kikusui, T., Onaka, T., and Ohta, M. (2009). Dog's gaze at its owner increases owner's urinary oxytocin during social interaction. Horm. Behav. 55, 434-441. doi: 10.1016/j.yhbeh.2008.12.002

Nagasawa, M., Mitsui, S., En, S., Ohtani, N., Ohta, M., and Sakuma, Y. (2015). Oxytocin-gaze positive loop and the coevolution of human-dog bonds. Science 348, 333-336. doi: 10.1126/science.1261022

Nagasawa, M., Mogi, K., Ohtsuki, H., and Kikusui, T. (2020). Familiarity with humans affect dogs' tendencies to follow human majority groups. Sci. Rep. 10:7119.

Ohkita, M., Nagasawa, M., Kazutaka, M., and Kikusui, T. (2016). Owners' direct gazes increase dogs' attention-getting behaviors. Behav. Process. 125:96. doi: 10.1016/j.beproc.2016.02.013

Pongrácz, P., Szapu, J. S., and Faragó, T. (2019). Cats (Felis silvestris catus) read human gaze for referential information. Intelligence 74, 43-52. doi: 10.1016/j.intell.2018.11.001

Schwab, C., and Huber, L. (2006). Obey or not obey? Dogs (Canis familiaris) behave differently in response to attentional states of their owners. J. Comp. Psychol. 120:169.

Téglás, E., Gergely, A., Kupán, K., Miklósi, Á, and Topál, J. (2012). Dogs’ gaze following is tuned to human communicative signals. Curr. Biol. 22:209.

Copyright $\odot 2021$ Koyasu, Kikusui, Takagi and Nagasawa. This is an open-access article distributed under the terms of the Creative Commons Attribution License (CC $B Y)$. The use, distribution or reproduction in other forums is permitted, provided the original author(s) and the copyright owner(s) are credited and that the original publication in this journal is cited, in accordance with accepted academic practice. No use, distribution or reproduction is permitted which does not comply with these terms. 